\title{
PERCURSOS INTERCONTINENTAIS. ARQUITETOS PARTINDO DE PORTUGAL NO SÉCULO XX
}

Tânia Beisl Ramos e Madalena Cunha Matos

Faculdade de Arquitetura - Universidade Técnica de Lisboa

taniabeislramos@clix.pt email: mcunhamatos@fa.utl.pt

\section{Resumo}

Após um reconhecimento do valor da obra de arquitetos portugueses nas antigas colônias no decorrer do século $X X$, e da importância da transferência de conhecimentos que a sua presença nesses territórios significou, faz-se um mapa dos caminhos seguidos na deslocação desses arquitetos entre a então 'metrópole' e os locais das visitas ou da emigração e uma análise dos padrões do seu estabelecimento nos trópicos. Após uma exposição dos dispositivos utilizados para visualizar esses caminhos, padrões e, ainda, interações entre profissionais, ensaia-se a utilização de ARS (Análise de Redes Sociais) para dar conta das complexidades da situação de copresença e assimetria nas redes por eles criadas, as quais incluem o eixo sul-sul entre a África e o Brasil.

Palavras-Chave: colônias portuguesas, Análise de Redes Sociais, arquitetos.

\begin{abstract}
After a recognition of the value of works designed by Portuguese architects in the colonies in the twentieth century, and of the importance of transfer of knowledge that their presence in those territories meant, this study aims to map the mobility of these architects between the 'metropolis' and the trips or emigrations' locations. It aims to identify the patterns of their establishment in the tropics. After a presentation of the procedure used to make viewable these paths, patterns, and also connections between professionals, ARS (Social Network Analysis) is used, allowing us to compare the complexities of the situation of co-presence and asymmetry in the networks the architects created. This study includes the south-south axis between Africa and Brazil. Keywords: Portuguese colonies, Social Network Analysis, architects.
\end{abstract}




\section{Caminhos conhecidos}

Em 2015 completam-se seiscentos anos de partidas de portugueses rumo ao sul (Figura 1). Se inicialmente eram de conquista, foram depois de descoberta, de comércio, de conversão e de conhecimento; e foram-se tornando mais e mais de ocupação, segundo um ritmo irregular e polaridades díspares nas costas visitadas.

Após seiscentos anos de sulcos, criados nas viagens de ida e de volta e naquelas, bem mais numerosas, de sentido único, os portugueses continuaram durante todo o século XX a sair para o sul a partir de Portugal. Até 1975, ano das independências africanas das então designadas 'províncias ultramarinas' , foi-se fazendo em crescendo a emigração para estas 'províncias'. Após esse ano, cessaram praticamente as partidas; vieram a retomar-se muito lentamente os caminhos, os mesmos caminhos, depois do fim das guerras civis. Entretanto, no continente americano, o Brasil e, em menor grau, a Venezuela, continuaram a atrair emigrantes, tendo o Brasil desempenhado um reforçado papel de destino alternativo durante a suspensão africana. A partida dos portugueses por esses caminhos abertos pela história, caminhos já percorridos, outrora por antepassados remotos e ontem ainda por conhecidos e familiares, fez-se incessantemente; por necessidade, por ambição, pelo desejo de mobilidade social e económica - nestes casos coincidente, ou dependente, da mobilidade física, real, dos corpos. Nessas viagens, as linhas invisíveis que os corpos vão descrevendo no espaço repetem-se, sobrepõem-se, emaranham-se, criam novelos de alta densidade, rarefazem-se nalguns destinos mais longínquos ou em cruzamentos em terras de interior. Sobre a superfície terrestre, formam um estrato de uma cultura muito específica, que no período do século XIX e XX não adquire visibilidade para as culturas alheias mas com elas coexiste e interage; formam padrões na geografia da terra.

Assim, nos vastos números que assim podemos visualizar, feitos de repetições, de gerações sucessivas, de anonimatos, não vemos os seres mas sim as trajetórias que eles descrevem no espaço. E no entanto, nesses mesmos traços, sabemos haver histórias individuais, únicas e muitas vezes notáveis. Entre a biografia e a estatística, a démarche cognitiva pode querer colocar-se num ponto de grande instabilidade - o de equilíbrio e visibilidade sobre ambas; no ponto de fuste de onde é possível olhar, entender, abarcar a realidade fugidia das consciências individuais e o peso e lentidão das tendências coletivas. Numa fase de grande oscilação e na noção da 
impossibilidade presente desse exercício, afigura-se no entanto possível dar uns primeiros passos numa marcação do terreno, esboçando uma cartografia mutável de agência e estrutura.

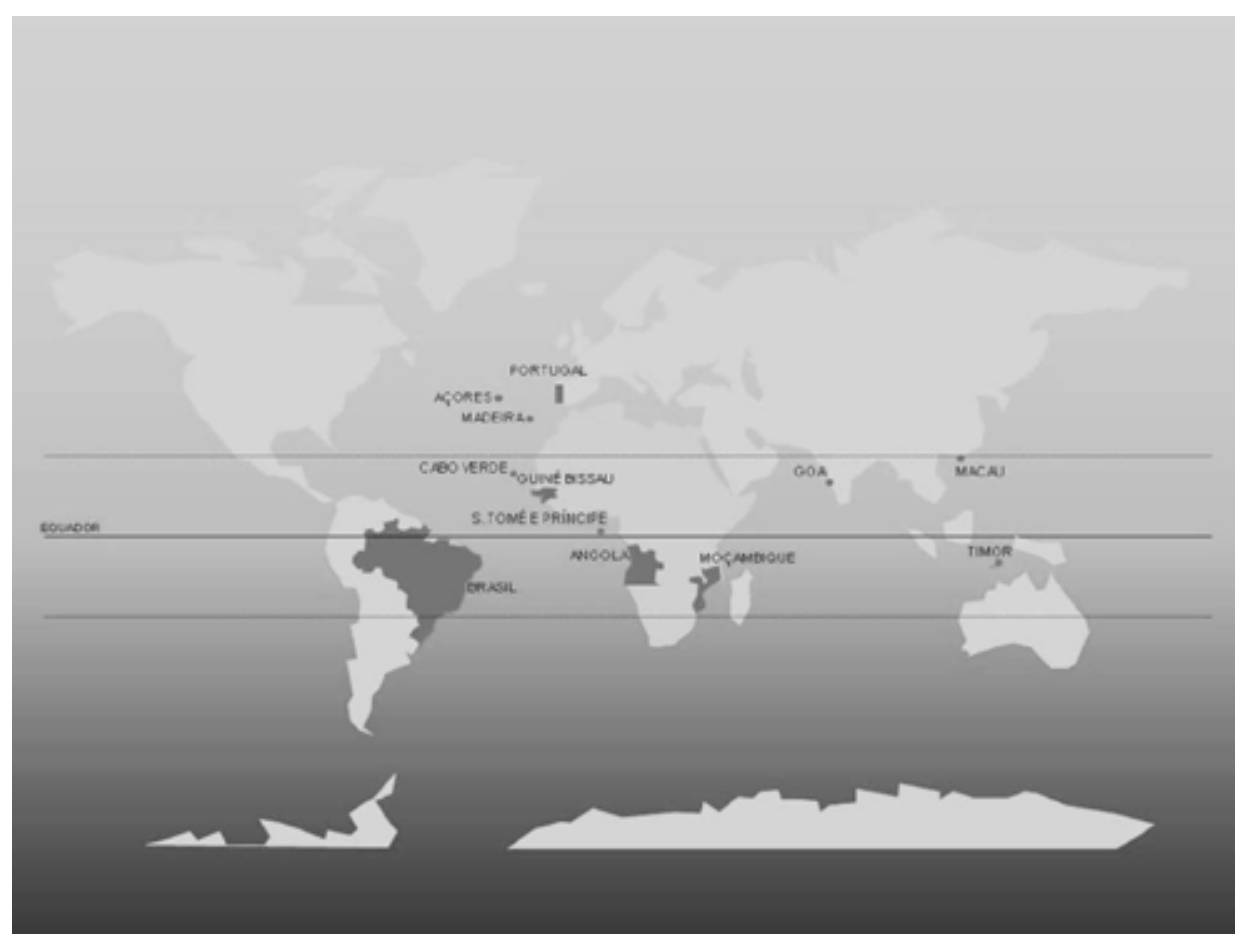

Figura 1: Âmbito geográfico das trajetórias dos arquitetos, apresentado de modo atemporal - antigas colônias/províncias ultramarinas nos séculos XIX e $\mathrm{XX}$.

\section{Arquitetos e urbanistas no século $X X$}

Quando se consciencializa a intenção de ocupação efetiva do território, e se transforma em seguida em agenda política, já surgiu o século XX. Então, e com maior incidência durante o Estado Novo (1926-1974), nos espaços africanos e asiáticos sob a dominação de Lisboa, os arquitetos portugueses tiveram um papel fundamental. Ele se manifestou na organização física do território e na construção de uma imensa variedade de programas funcionais. Passou pela realização de planos urbanísticos e regionais em escalas urbanas distintas e equipamentos destinados à segurança do território, às relações comerciais e ao desenvolvimento urbano: infraestruturas, aeroportos, escolas, hospitais, igrejas, edifícios públicos e privados, concebidos por arquitetos que buscaram nas províncias ultramarinas as condições de trabalho que a metrópole não oferecia. A procura de melhores condições de vida nas colônias foi o trampolim para os percursos traçados a partir de Portugal. Para as conseguir, atravessaram oceanos e, ou visitaram, ou permaneceram algum tempo, ou, de uma só vez em muitos casos, instalaram-se com intenção definitiva em locais completamente 
diferentes do seu habitat costumeiro e conhecido. Qualquer que seja o balanço e o juízo crítico sobre o colonialismo, tal como foi praticado ou imposto pelos poderes governamentais em Lisboa, estes profissionais deixaram uma herança histórica e cultural nos territórios de ocupação portuguesa que importa conhecer.

\section{Esquecimento do passado recente e omissão da história}

Verifica-se porém, até muito recentemente, um vazio no conhecimento desses artefactos e no dos agentes que os constituíram; sejam os construtores, operários, gente das famílias e do meio social; sejam os projetistas, autores da conceção e transmissores das tecnologias e dos universos formais aclimatados. Razões existem para este silêncio da história: a tristeza dos retornados, a saturação e desgaste de treze anos de guerrilhas em três territórios a milhares de quilómetros de casa, a guerra perdida dos militares, a conflitualidade interna na sociedade portuguesa entre os apoiantes e os opositores das independências ultramarinas, o trauma da perda, a rapidez com que tudo se resolveu afinal em independências sem espaço para negociações. Deu-se um afastamento mental, nos anos subsequentes, dessa matéria dolorosa, o assunto do passado colonial, e uma simultânea viragem radical para a integração europeia. O degelo do legado colonial fez-se lentamente; o do âmbito da arquitetura e do urbanismo foi dos mais tardios.

Observemos então alguns pontos de referência na construção do conhecimento daquela obra de urbanismo e de arquitetura.

Uma seleção de planos e levantamentos de mapas urbanos, herança relativa às cidades, viria a ser reunida e publicada, com ênfase nos planos urbanísticos elaborados no Gabinete de Urbanização do Ultramar em Lisboa, ainda na década de 1950. Compilado por Silveira (s/d), o Ensaio de Iconografia das Cidades Portuguesas do Ultramar é reconhecido como uma obra de referência. Após esta edição, a vasta produção desenvolvida e dispersa pelos três continentes estará praticamente ausente durante três décadas da visibilidade pública; escassa presença tem nos meios editoriais e no ensino; escassas referências surgem, significativamente, nas narrativas fundadores da historiografia da arquitetura moderna portuguesa. Os primeiros estudos surgem pela mão dos geógrafos.

\section{Registros da mobilidade}


Com o objetivo de se dispor de um quadro panorâmico da ação e obra dos arquitetos no século $X X$, e, inicialmente, apenas no período moderno, iniciou-se um trabalho de pesquisa em 2005. Ao pretender-se fazer uma cartografia prévia sobre o conhecimento existente sobre o tema, procurou-se reunir e sistematizar os dados dispersos e de fontes heterogéneas - as escritas e as orais, as atuais e as históricas, as sedeadas em Portugal e as oriundas dos territórios ex-colonizados. Com o avançar do trabalho, verificou-se que a paisagem observada se ia modificando - crescendo e densificando-se -, em função de novos dados surgidos em fontes mais uma vez heterogéneas. Observou-se também que essa situação de crescimento se iria manter e que seria imprevisível o grau e o ritmo de crescimento. Organizou-se uma primeira representação das trajetórias dos arquitetos, seguida de uma segunda representação, que já constitui um conjunto, assim como a que se seguiu, por imperativo da intenção de conhecimento e do próprio material em jogo: uma série de figuras representado a posição de cada arquiteto num espaço topológico e em redes entre eles estabelecidos.

A captação de novos dados sobre as biografias e as trajetórias profissionais é feita pela sobreposição de informações recolhidas pelas autoras em arquivos e em fontes díspares, nas quais avultam os estudos publicados.

\section{Elencando as fontes impressas}

Os estudos mais sistematizados são os de âmbito acadêmico, os periódicos da especialidade e os livros monográficos. Não se entra aqui na descrição das obras fundadoras da historiografia da arquitetura moderna, as quais porém forneceram naturalmente as bases para a pesquisa.

É por um trabalho de graduação que surge uma descrição da produção moderna na 'província' de Moçambique (ALBUQUERQUE, 1998); tema que é central na monografia Entre o adobe e o aço inox, da obra de José FORJAZ (1999). Também nesse ano, é publicada uma primeira síntese sobre as 'províncias ultramarinas' portuguesas (FERNANDES, 1999). A densificação que se procurou das referências a autores e locais de atuação recolhe dados em PEDREIRINHO (1994) e tem sequência na realização dos estudos acadêmicos (MARTINS, 2000, FERREIRA, 2008 e CORTÊZ, 2008). No meio universitário, é publicada a Revista UR (2005) dedicada às cidades africanas. São também publicados diversos 'álbuns fotográficos' retratando o passado em áreas geográficas distintas (AZENHA, 2001; GAMA, 2004). Na área da História da Arquitetura, surge o Geração Africana (FERNANDES, 2002) com segunda edição em 
2010. No trabalho de 1999 já referido, este autor havia elencado os principais intérpretes da arquitetura moderna nas ex-colônias; e irá desenvolver outros trabalhos sobre o tema em coautoria e sobre espaços geográficos e temporais distintos - séculos XIX e XX (FERNANDES, JANEIRO e NEVES, 2006; FERNANDES, JANEIRO e NEVES, 2006 e VELOSO, FERNANDES e JANEIRO, 2008). Estudos parcelares foram recentemente desenvolvidos (MILHEIRO, 2008), assim como estudos incidindo sobre a obra de autores individualizados (RAMOS e MATOS, 2010; MILHEIRO e FIGUEIRA, 2010). Em 2009, surge novo livro sobre o arquiteto mais precocemente publicado, Pancho Guedes (MUSEU COLECÇÃO BERARDO, 2009). No ano seguinte, a obra em três volumes coordenada por José MATTOSO, intitulado Património de Origem Portuguesa no Mundo, é publicada.

O estudo sistemático da mobilidade e das relações profissionais entre arquitetos portugueses tendo como principal destino as chamadas províncias ultramarinas teve início em 2005. Os primeiros resultados incindindo nas redes sociais dos arquitetos que trabalharam e viveram em Angola e Moçambique foram apresentados no IX DOCOMOMO Internacional (MATOS e RAMOS, 2006).

Um conjunto de trabalhos subsequentes procuraram analisar estas trajetórias sob diferentes pontos de vista e em diferentes escalas - do urbanismo e da arquitetura. Na pesquisa apresentada no 12th IPHS Conference (MATOS e RAMOS, 2006), foram analisados os planos urbanísticos sob a influência da cidade-jardim.

O estudo foi ampliado e apresentado no INHA (MATOS e RAMOS, 2007a). Os encontros e desencontros através do Atlântico entre o brasileiro Lucio Costa e os portugueses Raul Lino e Carlos Ramos são analisados no 70 Seminário DOCOMOMO Brasil (MATOS e RAMOS, 2007b). O desenvolvimento urbanístico da atual Maputo foi apresentado no ASAUK 2008 - UK Biennial Conference (MATOS e RAMOS, 2008a). O conceito de cidade-jardim que caracteriza um conjunto de cidades de Angola (Luanda, Benguela, Malanje e Cabinda) e Moçambique (Maputo, Quelimane e Tete) e a cidade de São Tomé foi o objeto do trabalho realizado para o X SHCU (MATOS e RAMOS, 2008b). Dois artigos foram elaborados sobre o tema em 2009. No DOCOMOMO Brasil (MATOS e RAMOS, 2009), foram analisados os espaços públicos que estruturam os núcleos centrais das cidades capitais Luanda e Maputo, e identificados alguns paralelismos com a produção arquitetónica moderna brasileira. E no outro, para a conferência AP 2009 (MATOS, RAMOS e COSTA, 2009), abordou-se o registo da 
implantação e evolução urbana das cidades sob o domínio português em África, vista sob a lente de Luis Silveira. Em 2010 a evolução do estudo com foco nas redes sociais é apresentado no First International Meeting EAHN (MATOS e RAMOS, 2010a) com continuidade no trabalho apresentado no primeiro General Working Group Meeting do Projeto Europeu COST 'European architecture beyond Europe: Sharing Research and Knowledge on Dissemination Processes, Historical Data and Material Legacy (19th-20th centuries)', em Marselha (MATOS e RAMOS, 2010b). Um artigo dá conta da amnésia na historiografia do moderno português quanto à produção colonial e é publicado no início de 2011 (MATOS, 2010). Toda a abordagem assente no uso dos grafos teve por origem um trabalho centrado, não no espaço colonial, mas no espaço português (KRÜGER, 2005).

\section{Métodos de análise}

A identificação dos dados visa então mapear os percursos profissionais dos arquitetos e urbanistas entre Portugal e as cidades e sítios das antigas colônias. Os dados foram inicialmente representados por meio de grafos estáticos, cujos nodos (arquitetos) estão posicionados segundo a data de chegada nas 'províncias', entre a década de 1940 e meados da década de 1970, altura em que o regime do Estado Novo cessa e é substituído. Estas balizas temporais não são, entretanto, definidas de modo rígido, sendo ultrapassadas, em ambos os sentidos, sempre que seja identificado algum ator cujo percurso se encaixe fora dos seus limites. O nome de cada ator, inserido na tabela, indica a data da sua chegada em alguma província portuguesa.

De modo a facilitar a identificação dos atores, foi decidido considerar os seguintes critérios: a formação dos arquitetos e o local de graduação - na ESBAL (Escola Superior de Belas Artes de Lisboa) e sua antecessora EBAL, na ESBAP (Escola Superior de Belas Artes do Porto) e sua antecessora EBAP, no exterior ou em local de formação 'desconhecido'; a duração da estadia, em 'pontual' ou de 'longa duração'; e a indicação da conexão destes atores com o Gabinete de Urbanização Colonial/Gabinete de Urbanização do Ultramar, GUC/GUU, por onde passaram muitos arquitetos antes da ida para os trópicos.

Refira-se ainda que após da Revolução dos Cravos em 1974, existiam em Portugal apenas duas escolas de arquitetura, ambas integradas nas 'Belas Artes'. A articulação destes dados com a data de presença e o local de graduação assume 
especial relevância, devido às circunstâncias políticas e linguagem arquitetónica dominante em cada 'escola' durante a década de 1950: enquanto na Escola do Porto o 'moderno' contava com o apoio do seu diretor, o arquiteto Carlos Ramos, na Escola de Lisboa dominava as linguagens do Beaux-Arts extemporâneo, do monumental-fascista e, para as construções domesticas, do pretenso localismo da 'casa portuguesa'.

As Figuras 2 e 3 apresentam os grafos relativos aos arquitetos formados em Lisboa (vermelho) e àqueles graduados no Porto (azul), e dados complementares quanto ao local de graduação e data de chegada às colonias.

A figura 2 permite verificar a articulação precoce dos arquitetos lisboetas com os territórios ultramarinos, quando comparados com os arquitetos do Porto. $O$ fato relaciona-se inicialmente, por um lado, com a proximidade ao GUU (Gabinete de Urbanização do Ultramar), por onde passaram muitos daqueles que migraram para os territórios ultramarinos, o que pode ter facilitado este percurso e contribuiu certamente para a motivação da transferência. E por outro lado, relaciona-se, no Porto, com o distanciamento dos arquitetos relativamente ao poder político e a menor força da imposição de uma linguagem do regime.

Um aspeto singular pode ser apontado às 'linhas sinuosas' entre dois nodos no grafo, o que significa o retorno destes arquitetos às colônias em datas distintas (Guilherme Rebelo de Andrade, Antonio Campino, Manuel Vicente, Luis Amaral, Simões de Carvalho e José Pinto da Cunha); enquanto os arquitetos Cristino da Silva, Pedro Vieira de Almeida, Keil do Amaral e Carlos Ramos deslocam-se pontualmente aos territórios ultramarinos. Cerca de três dezenas destes profissionais emigram para aqueles territórios entre as décadas de 1940 e 1970. 


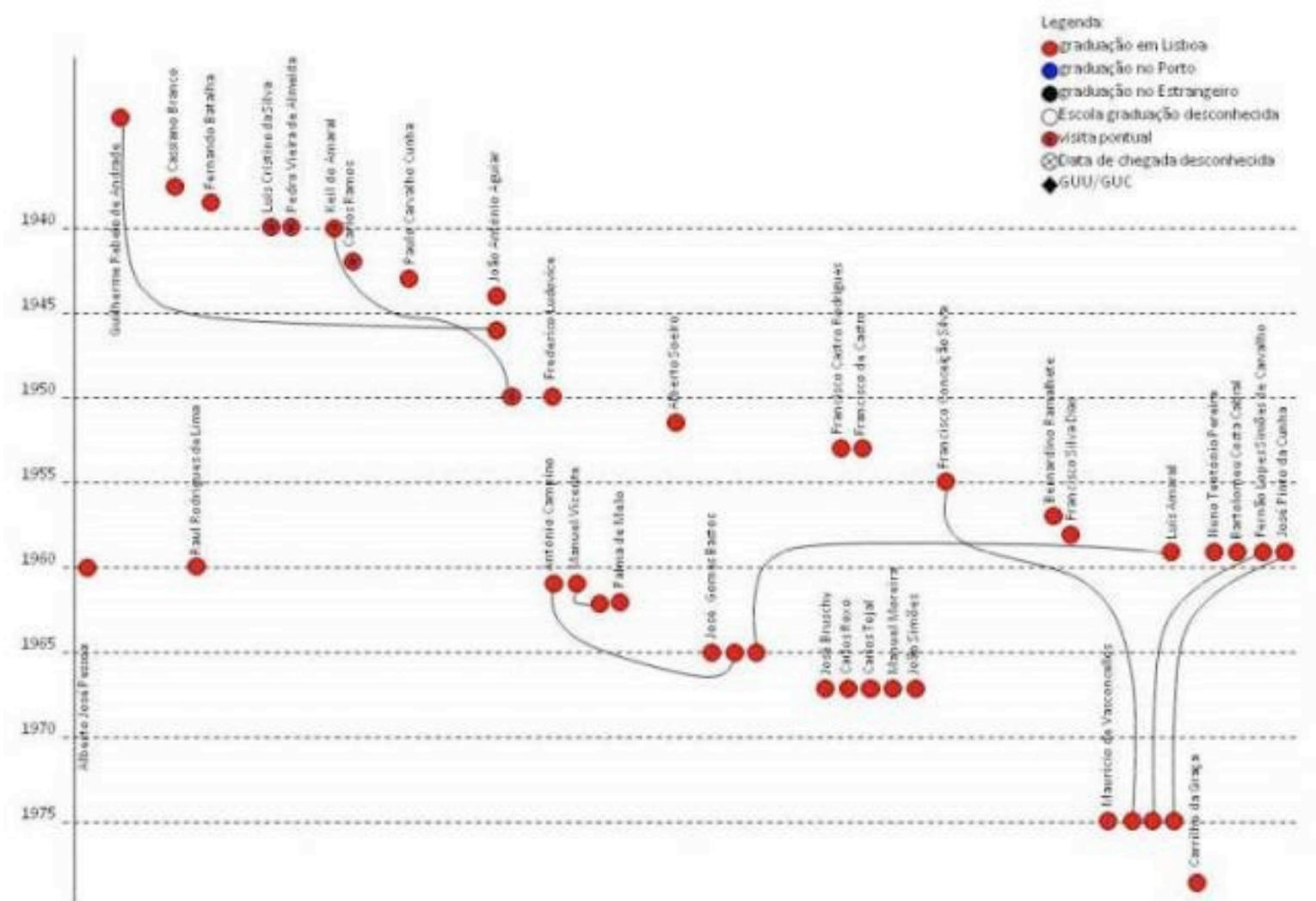

Figura 2: Registro da data de chegada dos arquitetos graduados na Escola de Lisboa nas antigas colônias/províncias ultramarinas.

Situação semelhante ocorre na figura que representa a mobilidade entre Portugal e as antigas colônias dos arquitetos graduados no Porto. Armênio Losa, Pancho Guedes, Antonio Veloso, Raul Chorão Ramalho, João José Tinoco partem de Portugal, retornam e tornam a partir, enquanto Cassiano Barbosa é o único arquiteto do Porto a deslocar-se pontualmente à província de Angola. A maior parte dos arquitetos portuenses migrou entre 1945 e 1965, sendo que, relativamente aos arquitetos lisboetas, o grupo dos arquitetos do Porto é numericamente semelhante. As razões para tal ultrapassam a questão da linguagem, uma vez que o 'moderno' era uma realidade nesta cidade. A questão da procura de melhores condições de vida associadas ao trabalho profissional está na raiz destas transferências. 


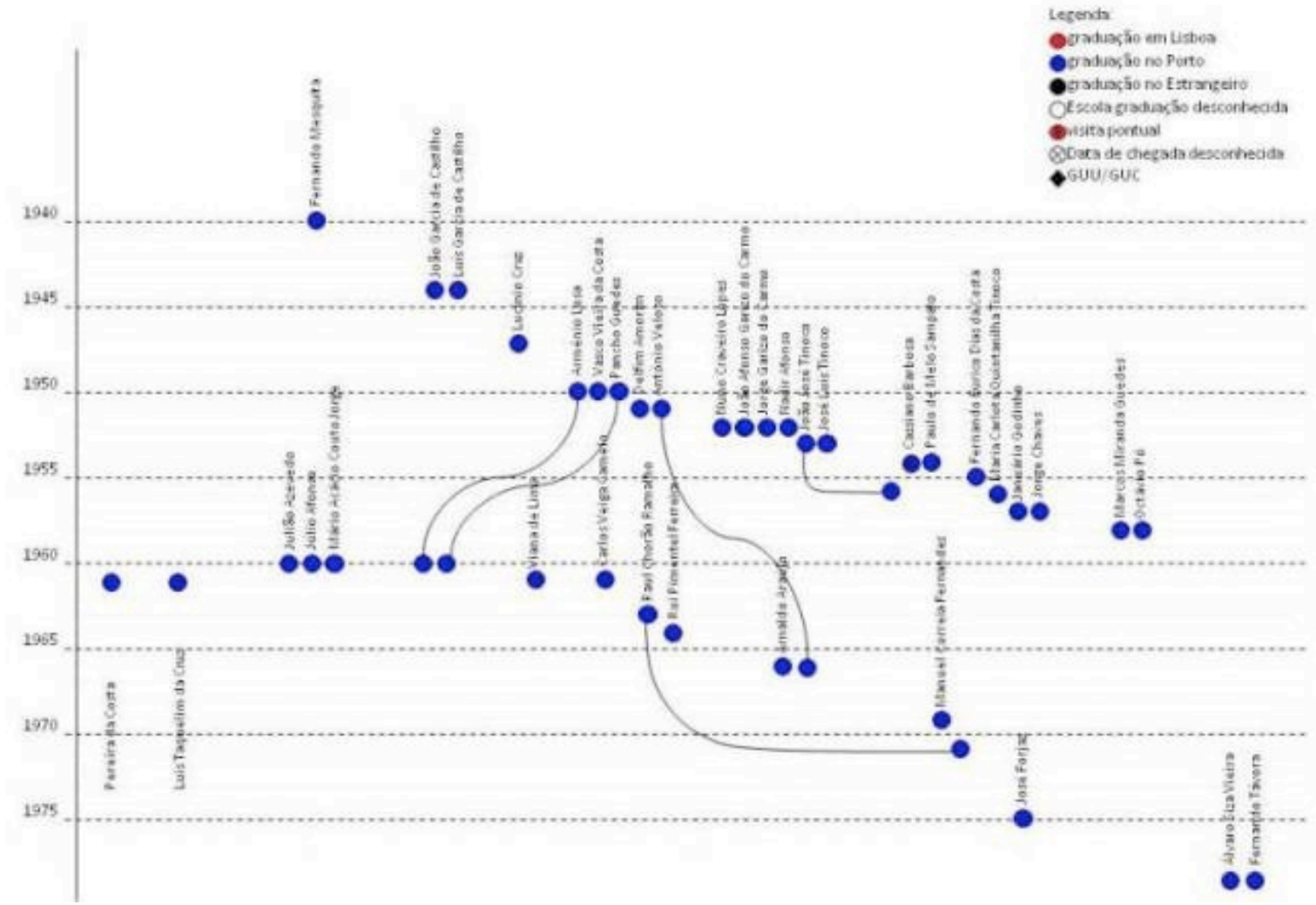

Figura 3: Registro da data de chegada dos arquitetos graduados na Escola do Porto nas antigas colônias/províncias ultramarinas.

A Figura 4 reúne num grafo único os dois grafos anteriores e acrescenta informações sobre os locais de graduação no exterior de Portugal ou desconhecido, bem como a data de chegada igualmente desconhecida. Dos 131 arquitetos que integram o grafo, estão identificados entre lisboetas e portuenses $70 \%$ dos arquitetos registrados. O local de graduação de cerca de $9 \%$ não foi identificado. Refira-se os arquitetos graduados no exterior (Raul Lino, Eduardo Anahory, Faria da Costa, Carlos Ivo, David Moreira da Silva, José Luis Porto e Vasco Regaleira), bem como aqueles que em diferentes momentos integraram a equipe de Le Corbusier (Simões de Carvalho, Vieira da Costa e Pinto da Cunha). Refira-se ainda a indicação de presença dos Gabinetes de Urbanização locais, em Angola e em Lourenço Marques (atual Maputo) na década de 1960. 


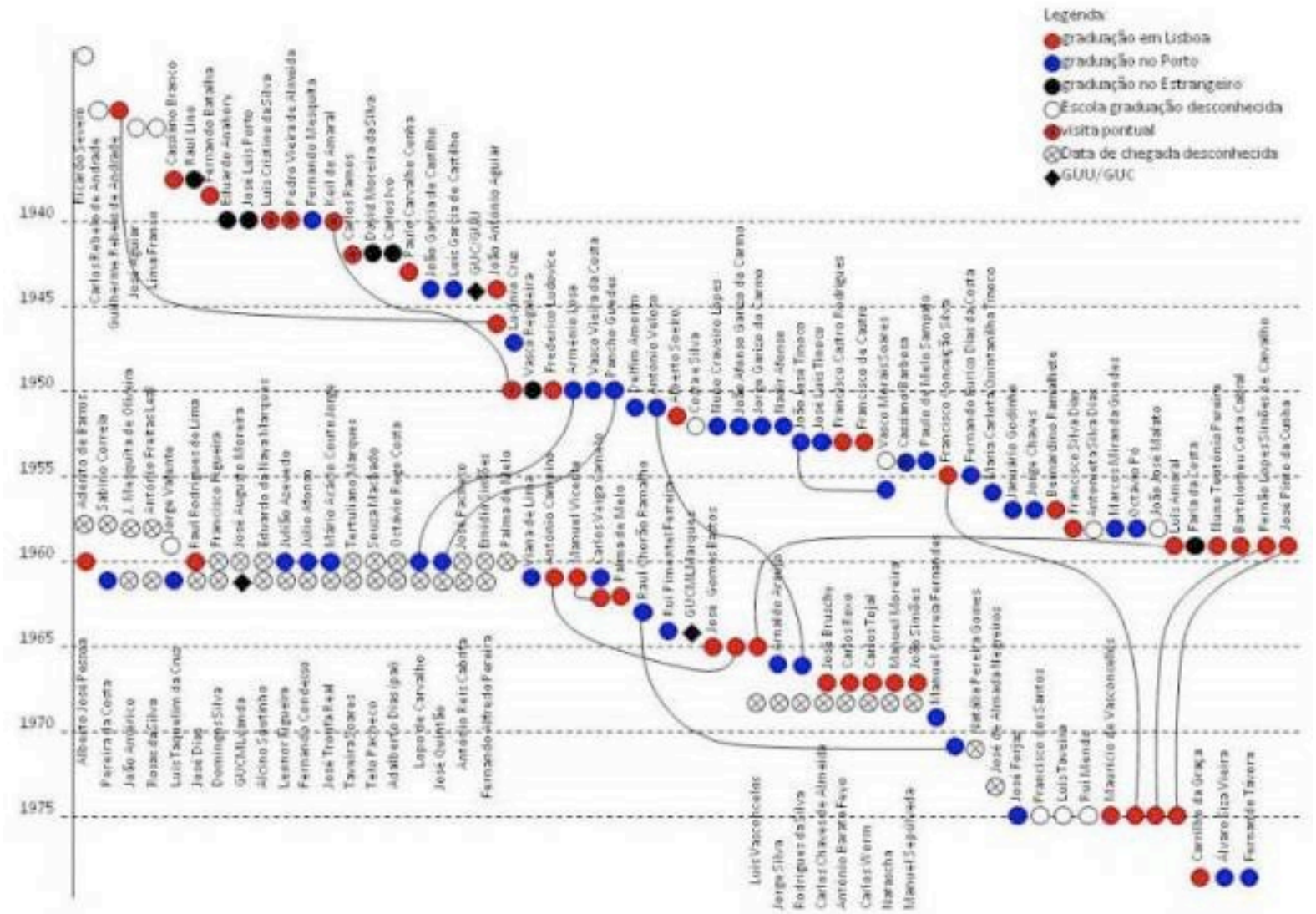

Figura 4: Registro geral da data de chegada dos arquitetos nas antigas colônias/províncias ultramarinas: graduados nas Escolas de Lisboa e do Porto, bem como os graduados no exterior. Indicação daqueles com data de chegada desconhecida.

Entre os 131 arquitetos que integram o grafo, 20\% estabeleceram relações de trabalho em uma ou mais colônias. Estas conexões foram identificadas segundo o local onde trabalharam. A Figura 5 apresenta as conexões entre os profissionais com produção arquitetónica em Angola e a Figura 6 apresenta os vínculos identificados em Moçambique.

O registro das conexões indica as várias coautorias em projetos e obras construídas, assim como relacionamentos profissionais em órgão público gabinete de urbanização local. A leitura dos grafos permite identificar um número superior de conexões entre os arquitetos em Moçambique. Entretanto, não é possível estabelecer padrões de associação entre vínculos profissionais ou de amizade, nem identificar graus de conexão entre os atores. Para ultrapassar esta situação, recorreu-se à metodologia da Análise de Redes Sociais (ARS). 


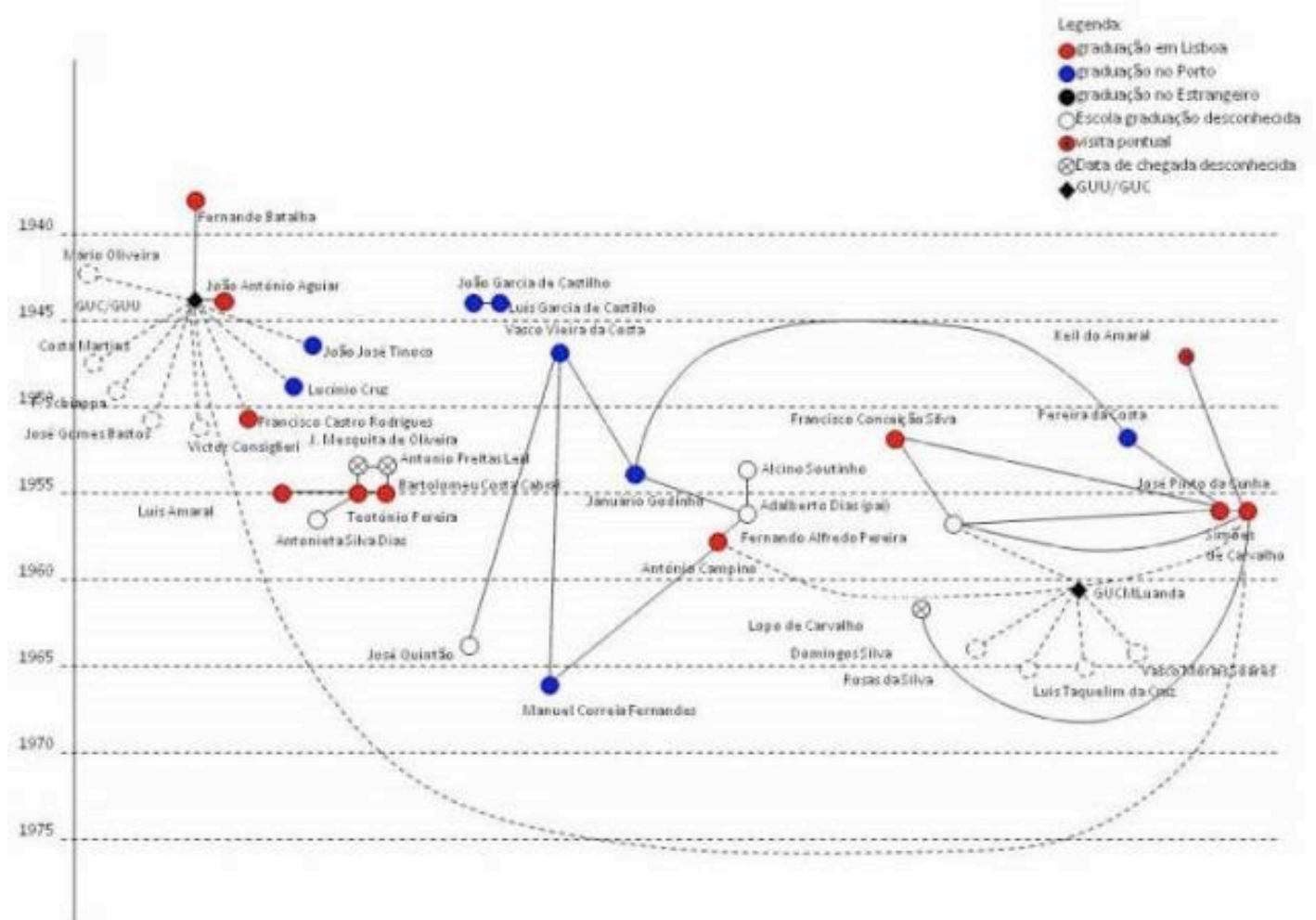

Figura 5: Relacionamentos profissionais entre os arquitetos portugueses em Angola.

\section{Medição das conexões}

A Análise de Redes Sociais analisa as relações entre um conjunto de atores de modo a identificar padrões de interação (SCOTT, 2000; QUIROGA, 2005; WASSERMAN e FAUST, 2006). O objetivo principal consiste em identificar os arquitetos conectados numa rede de relacionamentos profissional e social. Estas relações são captadas por um grafo dinâmico e são representadas por meio de sociogramas.

A análise destas conexões permite identificar os atores que se encontram em posições privilegiadas na rede e a sua capacidade de aceder mais facilmente às informações, analisando a proximidade ou o distanciamento entre estes atores.

E uma vez que a metodologia permite o registro da mobilidade e ligações entre arquitetos de modo contínuo, torna-se possível inserir novos atores em Base de Dados. Identificadas as conexões entre um conjunto de atores, pretende-se medir estas conexões. 


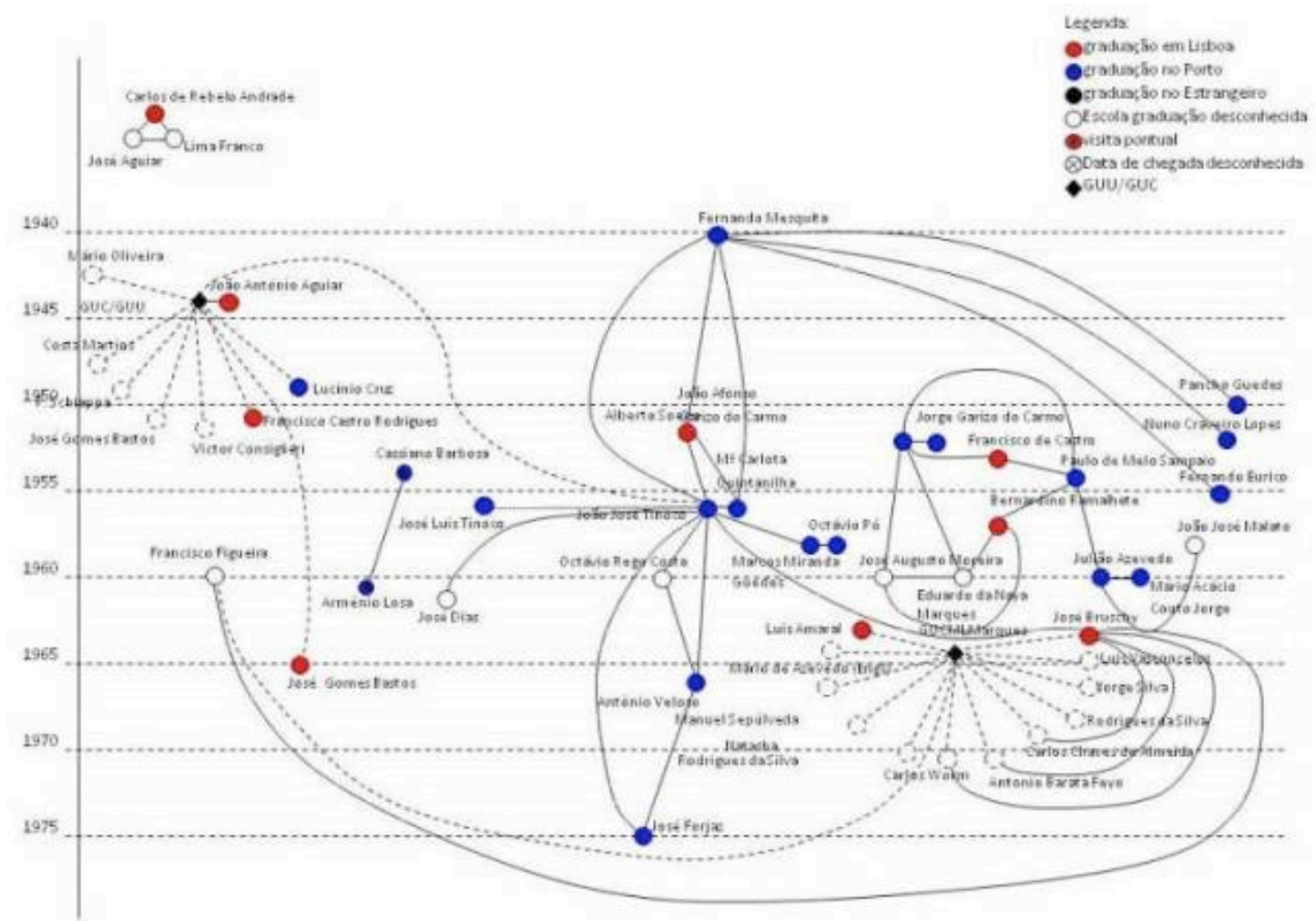

Figura 6: Relacionamentos profissionais entre os arquitetos portugueses em Moçambique.

A rede social estruturada no momento consta de 161 arquitetos. Estão representados na Figura 7, de acordo com o local de graduação (Lisboa - vermelho; Porto - azuis; exterior - cinza e desconhecida - branco). Neste sociograma, as conexões existentes entre lisboetas e portuenses ocorrem por meio daqueles que estiveram pontualmente nas províncias ultramarinas e que estabeleceram vínculos com os que lá estiveram mais tempo.

Apenas ilustrativas, as Figuras 8 [A, B] representam todas as possíveis conexões entre grupos de arquitetos de um mesmo local de graduação, explorando os vínculos entre eles. Enquanto a Figura 9 apresenta diversas conexões entre os arquitetos, por meio da identificação do país onde cada um exerceu a profissão, i.e., apresenta relacionamentos de atores entre dois ou mais países. Há arquitetos portugueses que trabalharam no Brasil e também nos demais países/ territórios, com exceção de Timor e Goa.

O mesmo conceito é apresentado na Figura 10, que entretanto identifica os respectivos arquitetos. Exemplo: o arquiteto Raul Chorão Ramalho é autor da Escola Portuguesa em Macau, como também da Embaixada de Portugal em Brasília. 


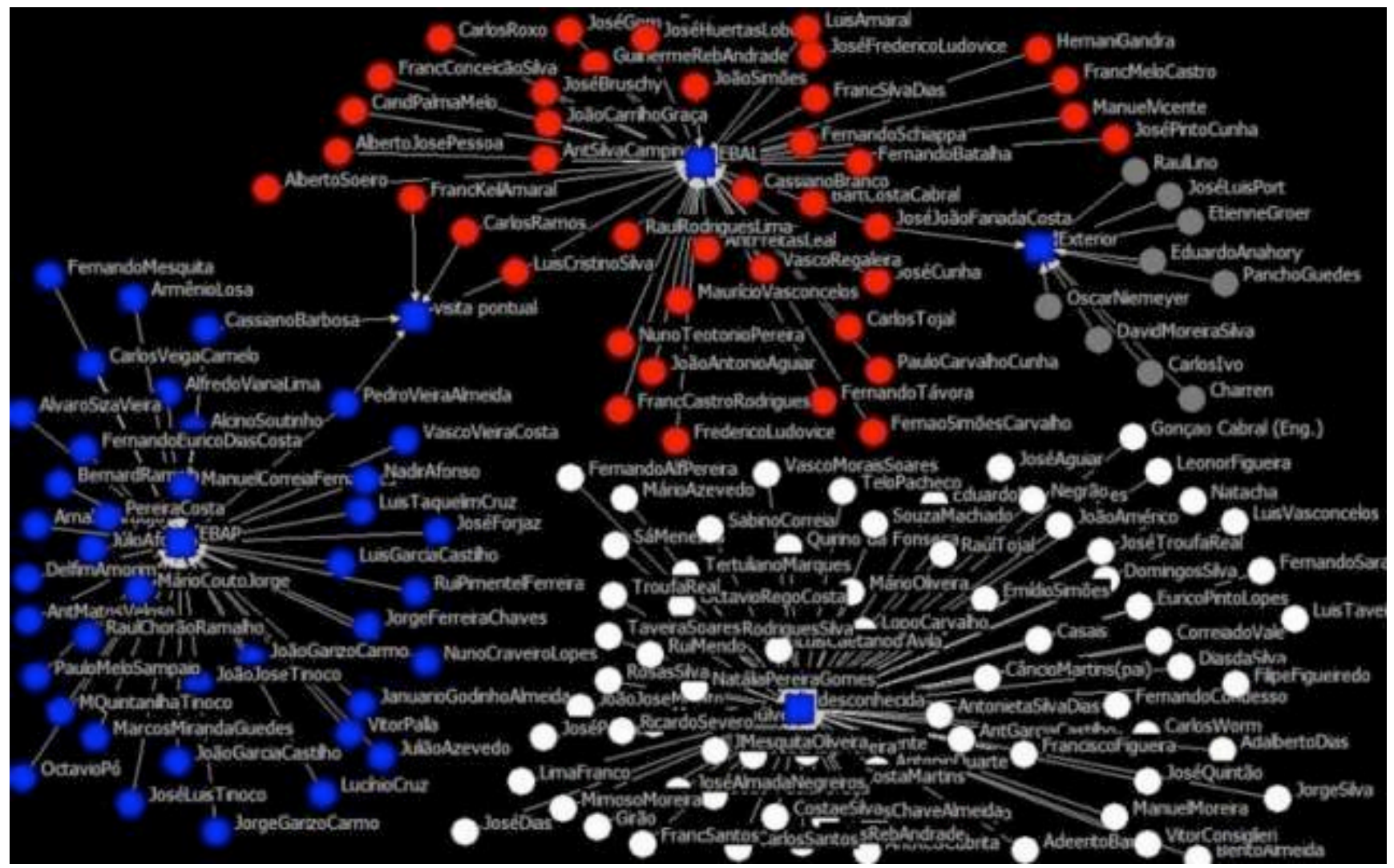

Figura 7: Sociograma dos 161 arquitetos portugueses segundo o local de graduação: Lisboa, Porto, Exterior e Desconhecida.
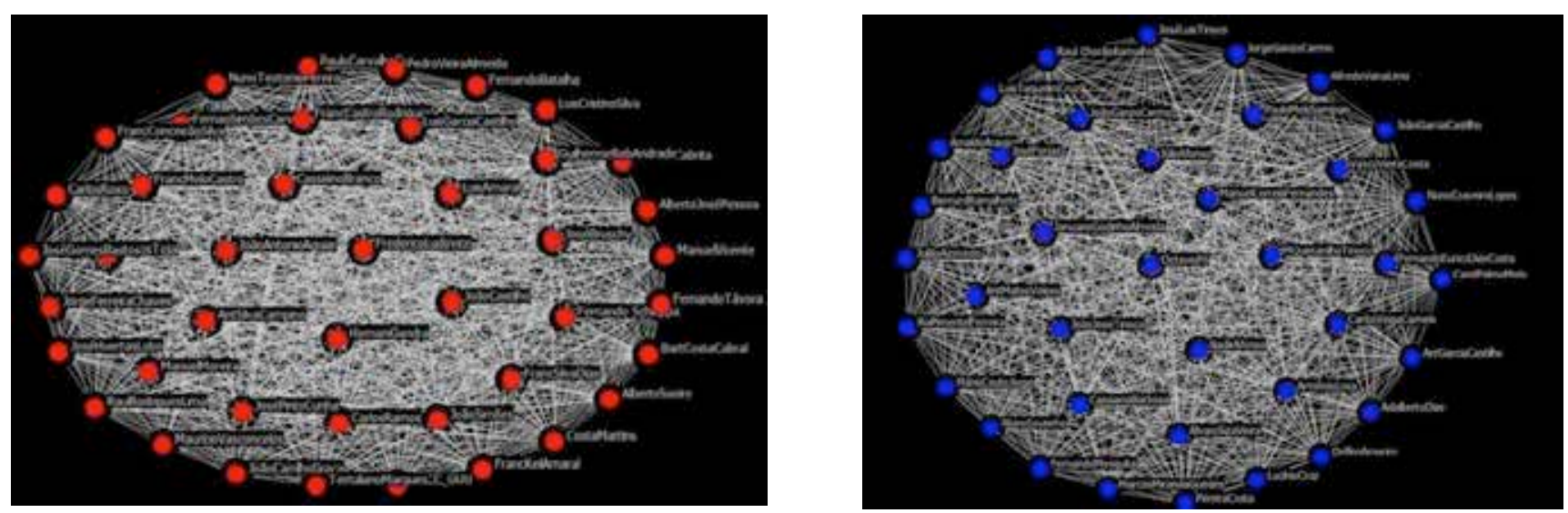

Figura 8[A, B]: Sociogramas do total de conexões possíveis entre arquitetos portugueses segundo o local de graduação: Lisboa e Porto. 


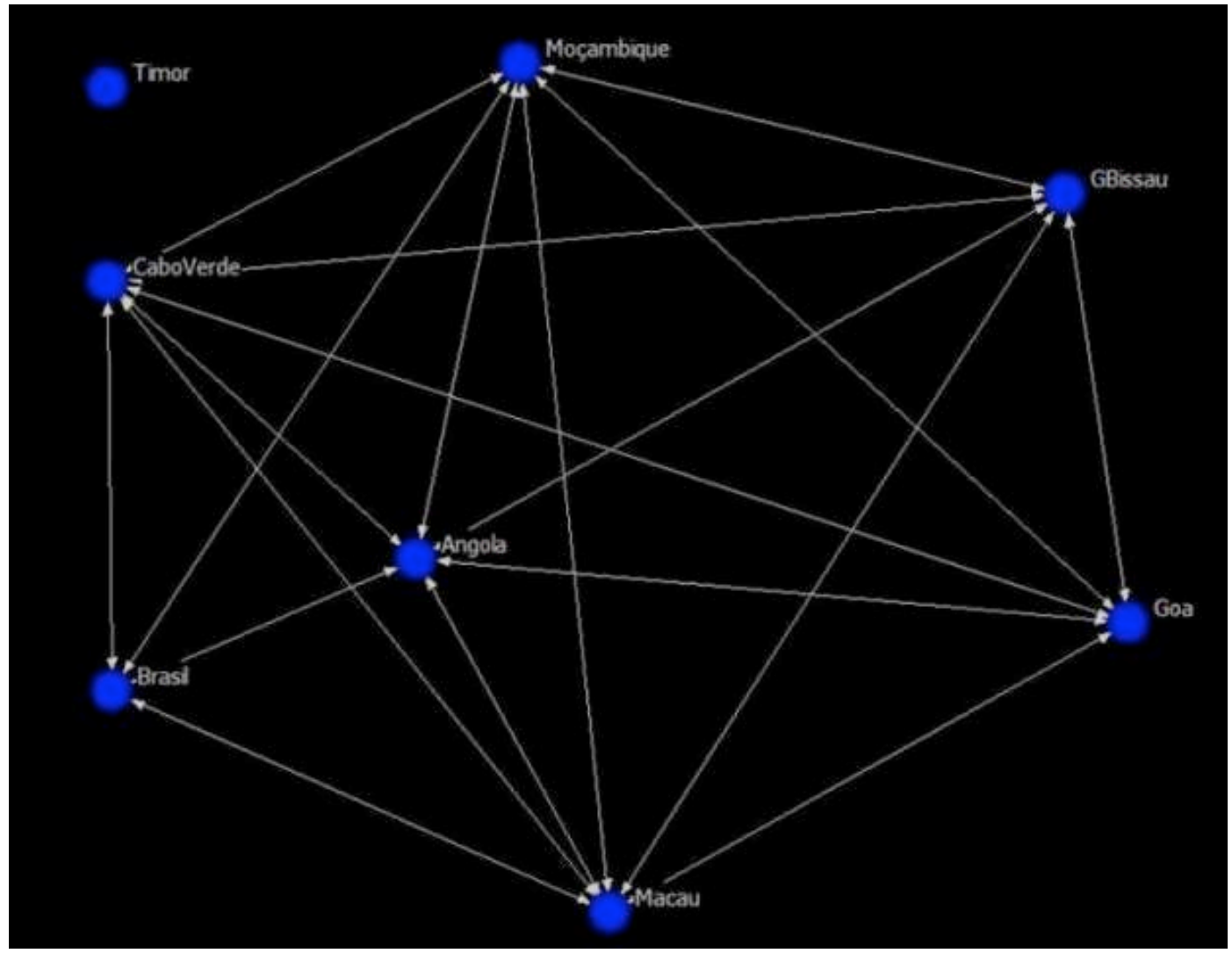

Figura 9: Sociograma síntese das conexões entre arquitetos, representados pelos seus territórios de origem.

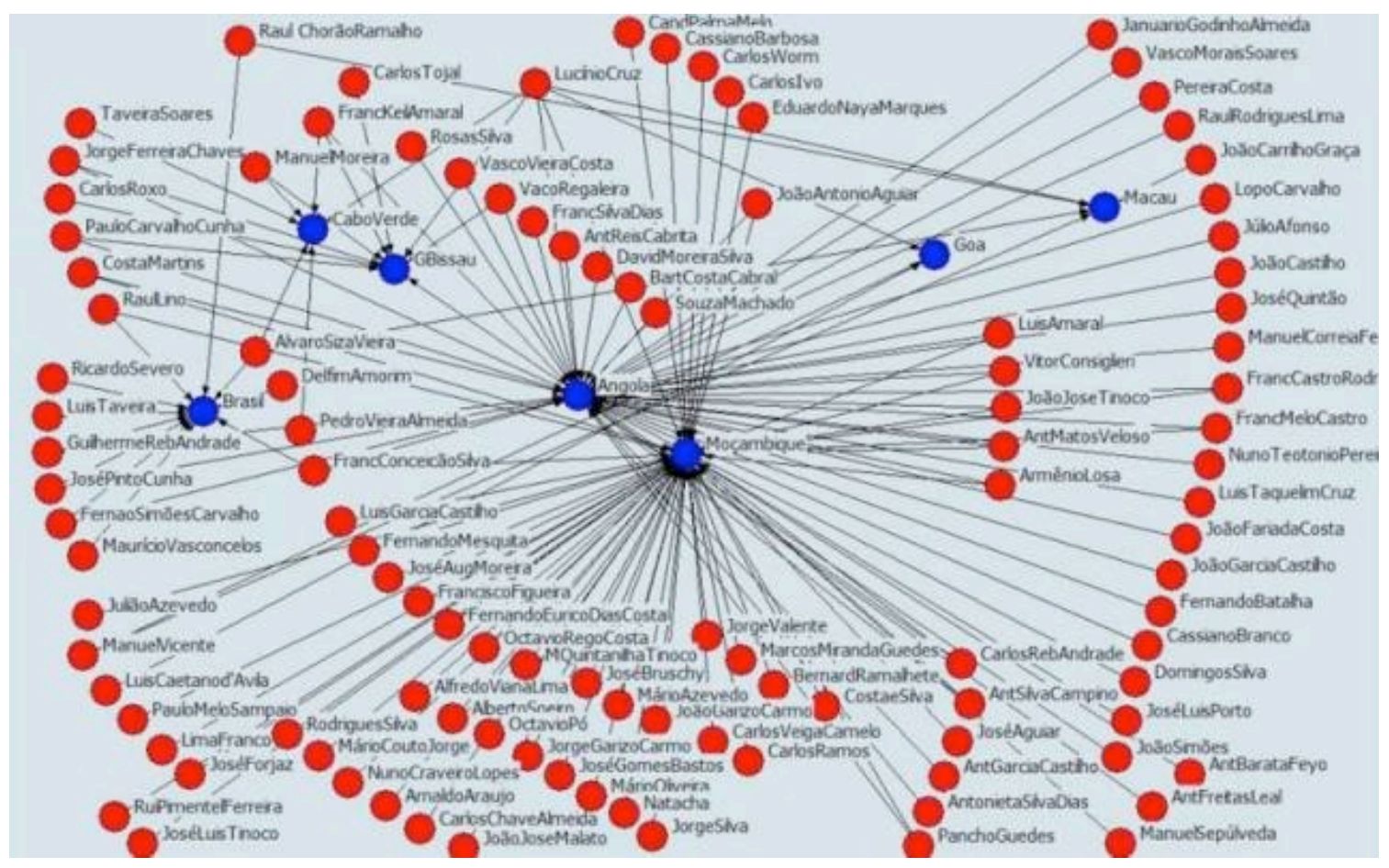

Figura 10: Sociograma das conexões entre o total de arquitetos e os territórios onde projetaram e construíram obras. 
grupos, cujos atores estão conectados entre si. Os arquitetos sem conexão no sistema foram retirados. Os nodos em círculo representam os arquitetos graduados em Lisboa, e os triângulos os graduados no Porto.

O maior grupo é constituído por 66 arquitetos em rede. João Tinoco, Brusky e Simões de Carvalho são os arquitetos melhor posicionados na rede, o que implica num maior número de conexões, e consequentemente maior número de alternativas de acesso a outros atores e menor dependência de outros. João Tinoco e João Aguiar possuem uma maior capacidade de controlar a passagem de informação na rede.

O sociograma permite identificar vínculos entre os arquitetos e, por sua vez, identificam a produção arquitetónica segundo as conexões.

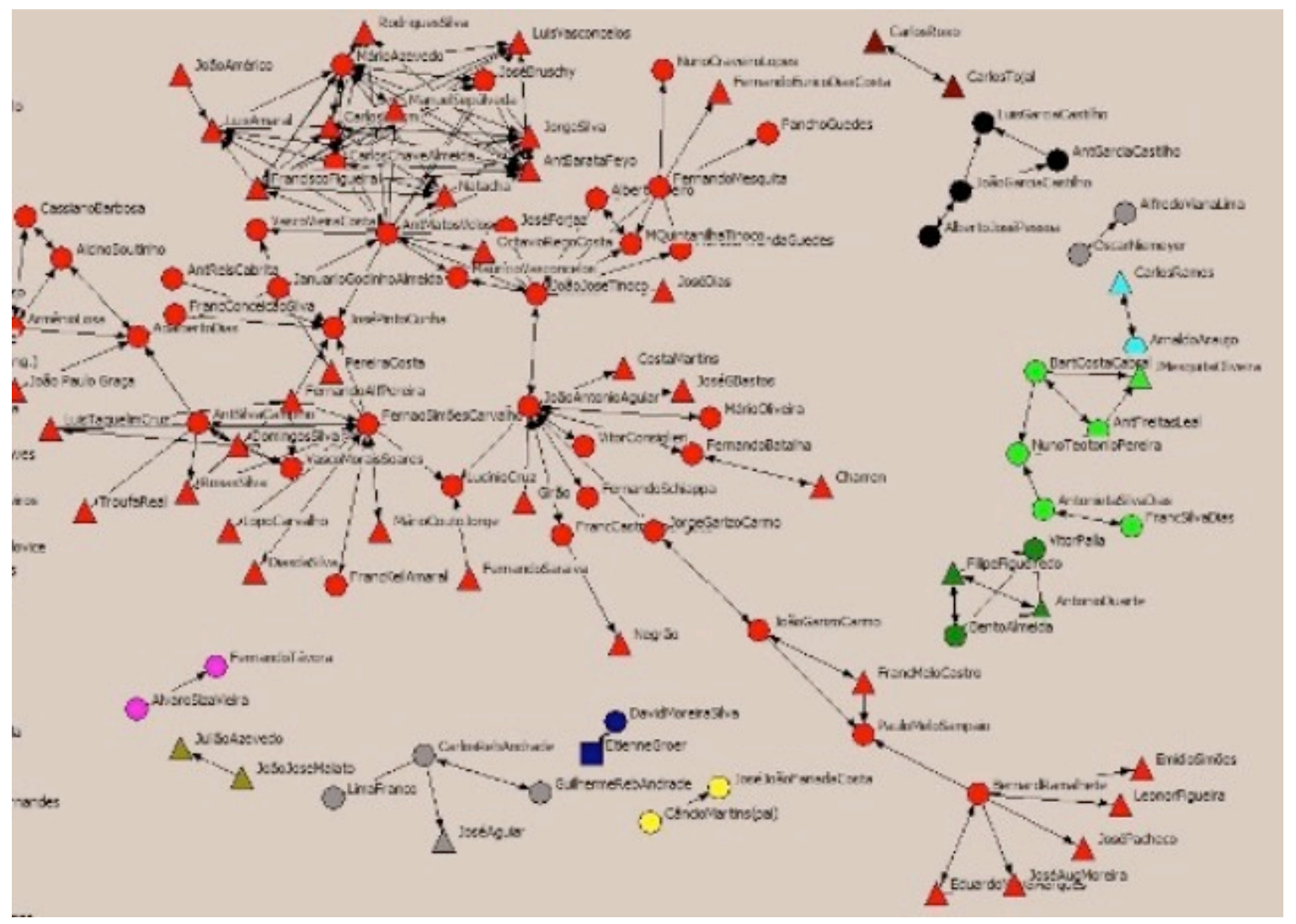

Figura 11: Sociograma das conexões entre os arquitetos portugueses identificados segundo os componentes que estruturam a rede.

\section{Conclusões}

A identificação dos dados e a sua colocação em relação topológica permitiu mapear os percursos profissionais dos principais arquitetos e urbanistas entre Portugal e as cidades e sítios das antigas colônias. Porém, o conhecimento desta mobilidade é assumido como um work in progress, uma vez que o registro das conexões entre estes profissionais é um processo contínuo e se prolonga no tempo; o passado aqui 
considerado é demasiado recente - não em termos de unidades objetivas de tempo, mas em termos de vivências, dores e conflitos armados. Continuamente têm surgido notícias de arquitetos, já conhecidos ou novas individualidades na rede, de relações de trabalho, de datas e de locais, que obrigam a um redesenho do conjunto e desequilibram os quadros obtidos. Por outro lado, vai crescendo também o conhecimento sobre as obras produzidas e sobre os projetos e suas circunstâncias. Hiatos persistirão durante muito tempo, dados incompletos, contraditórios e imprecisos. Julga-se que o mapeamento dos indivíduos e suas trajetórias geográficas, seus encontros e desencontros, e seu papel no conjunto mais vasto, é um dispositivo necessário e adequado à índole fuzzy do problema, à natureza incerta do levantamento de dados e ao ritmo desordenado da sua obtenção - enquanto mantêm transitoriamente os dados em relação segura. Simultaneamente, vai-se definindo o próprio problema: o que está em causa deixou tanto de ser o universo claramente distinto dos indivíduos e sua identidade, assim como o universo dos grandes números, onde se distinguem apenas os padrões resultantes. Aqui, surgiu como objeto de estudo o universo intermédio, dos números grandes mas resultantes de nodos que podem ainda ser nomeados.

A arquitetura persistiu e atravessou com alguns estragos o tempo dos trinta e cinco anos após as independências. A deterioração das construções em concreto armado está patente, com algumas exceções, mas a especulação e o imobiliário agressivo fez mais pela destruição desse legado do que as guerras fratricidas que se travaram nos dois grandes países de Africa. Edifícios de equipamentos coletivos de grande porte são demolidos para se erguerem complexos de usufruto privado: torres de escritórios e grandes malls comerciais em parede cortina. Os mais qualificados edifícios do período colonial são derrubados ou estão sob ameaça. Movimentos e ações de reapropriação do legado partilhado têm surgido, nas colónias como na antiga metrópole; a documentação é indispensável para a preservação e a valorização dessa arquitetura. Para o conhecimento dos artefactos construídos, é necessária a componente humana; para percurso das ideias, das tecnologia e das práticas construtivas, é indispensável seguir os homens e as mulheres que os transportam.

Apresentaram aqui alguns extratos desse trabalho de cartografia, que inclui ramificações nos continentes asiático e americano e cruzamentos do território de uma antiga colónia para outra. O avanço da pesquisa depende do trabalho paciente de 
reconstituição de trajetórias e identificação de lugares, caminhos, datas, obras, projetos, pessoas. A retomada lenta do trajetos para sul cruza-se agora com a densidade crescente dos novos e finalmente também antigos trajetos horizontais, que vão do Brasil para os territórios africanos outrora portugueses.

\section{Referências}

ALBUQUeRQUE, Antônio (1998). Arquitetura Moderna em Moçambique. Inquérito à Produção Arquitetônica em Moçambique nos últimos 25 Anos do Império Colonial Português. 1949-1974, Dissertação de Graduação, Coimbra: DA-FCT- UC.

AZENHA, Antônio (2001). África Desaparecida. Lisboa: Tilgráfica.

CORTÊZ, Carla (2008). Moderno Brasileiro em Moçambique. Monografia de Graduação em Arquitetura e Urbanismo - UFP, Recife.

FERNANDES, José Manuel (1999). Arquitetura e Urbanismo no Espaço Ultramarino Português in F. BETTENCOURT e K. CHAUDHURI (Eds), História da Expansão Portuguesa, vol. V - 1930-1998, Lisboa: Círculo de Leitores.

(2002). Geração Africana. Arquitetura e Cidades em Angola e Moçambique, 1925-1975. Lisboa: Livros Horizonte (2a ed. 2010).

FERNANDES, José Manuel, JANEIRO, Ma Lurdes e NEVES, Olga (2006). Moçambique 1875/1975. Cidades, Território e Arquiteturas. Lisboa: Printer Portuguesa.

FERREIRA, André (2008). Obras Públicas em Moçambique. Inventário da produção arquitetônica executada entre 1933 e 1961. Lisboa: Edições Universitárias Lusófonas.

FORJAZ, José (1999). Entre o adobe e o aço inox: ideias e projetos. Lisboa: Caminho.

GAMA, Curado da (2004). Era uma vez... Moçambique, Lisboa: Quimera.

KRÜGER, Mário (2005). Um olhar sobre o século XX. Produção arquitetônica e afinidades eletivas, Conferência na Faculdade de Arquitetura, Universidade Técnica de Lisboa.

MARTINS, Isabel (2000). Luanda. A cidade e a arquitetura. Tese de Doutoramento, Faculdade de Arquitetura. Porto, FAUP.

MATOS, Madalena Cunha (2010). Colonial Architecture and Amnesia in OASE 82, L'Afrique, c'est chic. Architecture and Planning in Africa, 1950-1970, ISBN 978-90-5662775-1.

MATOS, Madalena Cunha e RAMOS, Tânia Beisl (2010b). Recapturing The Network. Developing social network analysis on Portuguese architects in the colonies, General Working Group Meeting, Project COST 'European architecture beyond Europe'.

(2010). Recapturing The Network: A position paper in 1st International Meeting EAHN - European Architectural History Network, Guimarães, Book of Abstracts, p. 83, CD, full text, ISBN 978 98995563-9-3/978-989-96163-2-5.

(2008a). Portuguese Architectural Networks, in Lourenço Marques/Maputo.

Architecture and City Image, ASAUK 2008, University of Central Lancashire, Preston. 
(2008b). Amenizar os trópicos: Desenhando cidades-jardim nas excolônias portuguesas in $\mathbf{X} \mathbf{S H C U}$, UFP, Recife.

(2007a). Portuguese architects abroad. The cases of Angola and Mozambique in INHA, Construire au-delà des frontières. Une perspective historique sur les réseaux transnationaux d'échange et d'expertise architecturale en Afrique subsaharienne, Paris.

(2007). Um Encontro, um Desencontro. Lucio Costa, Raul Lino e Carlos Ramos in $7^{\circ}$ Seminário DOCOMOMO Brasil, UFRS, Rio Grande do Sul.

(2006a). Going South: the garden city concept in urban plans made by Portuguese architects in the colonies during the 20th Century in $\mathbf{1 2}^{\text {th }}$ IPHS Conference, New Delhi.

(2006b). A Two-Way Street: Migrants of the Modern across Portuguesespeaking countries in IX International DOCOMOMO Conference, Ankara, (no prelo).

MATOS, Madalena Cunha, RAMOS, Tânia Beisl e COSTA, Luis Patricio (2009). Planned and unplanned towns in former Portuguese colonies in Sub-Saharan Africa: an analysis of Silveira's Iconografia in AP 2009 Conference. The African City Centre Re(sourced), disponível em: http://web.up.ac.za/sitefiles/file/44/1068/3229/9086/African\%20Perspectives/PDF/Papers/mat os.pdf, acesso em 12 janeiro 2010.

MATTOSO, José (Coord.) (2010). Património de Origem Portuguesa no Mundo, 3 vol., Lisboa: Fundação Calouste Gulbenkian.

MILHEIRO, Ana (2008). As coisas não são o que parecem que são. Opúsculo 15, Dafne Editora, Porto.

MILHEIRO, Ana e FIGUEIRA, Jorge (2010). Moderno colonial. Património escolar em Angola construído durante o Estado Novo português in $3^{\circ}$ Seminário Docomomo $\mathbf{N}-\mathbf{N E}$, João Pessoa.

MORAIS, João. Maputo (2001). Patrimônio da Estrutura e Forma Urbana. Lisboa: Livros Horizonte.

MUSEU COLECÇÃo BERARdo (2009). Pancho Guedes. Vitruvius Mozambicanus. Lisboa: FAMC - Coleção Berardo.

PEDREIRINHO, J. M. (1994). Dicionário dos Arquitetos activos em Portugal do século I à atualidade. Edições Afrontamento, Porto.

QUIROGA, Á. et al (2005). Talleres de autoformación con programas informáticos de análisis de redes sociales Borrador.

RAMOS, Tânia Beisl e MATOS, Madalena Cunha (2005). Recepção da Arquitectura Moderna Brasileira em Portugal - registos e uma leitura in VI DOCOMOMO BRASIL, Niterói, Anais p.164-166 e CD-Rom.

(2010). Presenças e Projectos de Simões de Carvalho em Portugal, em Angola e no Brasil in III Seminário DOCOMOMO Norte Nordeste. Anais em CD-Rom ISBN 978-85-237-0560-2. Caderno de Resumos ISBN 978-85-237- 0559-6. Universidade Federal da Paraíba.

ROSSETTI, Ma Grazia (1991). Cittá Coloniale - Città Africana. Considerazione e manutenzione dello spazio urbano in Piergiorgio Ramundo, Progettare perl a 
riconstruzion. La cooperazione universitária in Angola. Gangemi Editore, p.167-188, Roma.

SCOTT, J. (2000). Social Network Analysis, Sage, Londres.

UR (2005). Cadernos da FA-UTL no 5, Cidades Africanas, Lisboa.

VELOSO, António, FERNANDES, José Manuel e JANEIRO, Ma Lurdes (2008). João José Tinoco. Arquitecturas em África. Lisboa: Livros Horizonte.

WASSERMAN, S. and FAUST, K. (2006). Social Network Analysis: Methods and Applications. Cambridge. Cambridge University Press, 1994, 14th printing. 